\title{
Diabetic retinopathy: recent advances towards understanding neurodegeneration and vision loss
}

\author{
BARBER Alistair J. \\ Penn State Hershey Eye Center, Penn State Hershey College of Medicine, Milton S. Hershey Medical Center, Hershey, PA 17007, USA
}

Received December 24, 2014; accepted February 2, 2015; published online May 6, 2015

\begin{abstract}
Diabetic retinopathy (DR) is one of the most common retinal diseases world-wide. It has a complex pathology that involves the vasculature of the inner retina and breakdown of the blood-retinal barrier. Extensive research has determined that DR is not only a vascular disease but also has a neurodegenerative component and that essentially all types of cells in the retina are affected, leading to chronic loss of visual function. A great deal of work using animal models of DR has established the loss of neurons and pathology of other cell types, including supporting glial cells. There has also been an increased emphasis on measuring retinal function in the models, as well as further validation and extension of the animal studies by clinical and translational research. This article will attempt to summarize the more recent developments in research towards understanding the complexities of retinal neurodegeneration and functional vision loss in DR.
\end{abstract}

retina, diabetes, neurodegeneration, visual function, vascular function, apoptosis, synapse, dendrite

Citation: Barber AJ. Diabetic retinopathy: recent advances towards understanding neurodegeneration and vision loss. Sci China Life Sci, 2015, 58: 541-549, doi: $10.1007 / \mathrm{s} 11427-015-4856-\mathrm{x}$

Over the last 20 years the concept that neurodegeneration plays a part in diabetic retinopathy (DR) has become widely accepted. A central part of the neurodegeneration hypothesis was that death of neurons was the primary cause of vision loss in diabetic retinopathy (DR). This was a simplistic approach towards a complex disease, and more recent evidence suggests that other processes may contribute to reduced neuronal function and vision loss before cell death occurs; alongside changes in the regulatory mechanisms of the retinal vasculature. Neurodegeneration is usually characterized as being chronic in nature, resulting in a cumulative loss of neurons, photoreceptors and glial cells, as well as associated pathologies in the vasculature. Evidence from basic research using animal models of DR supports the notion that apoptosis of the retinal tissue is elevated by diabetes, leading to a loss of different cell types as well as a thinning of retinal layers. The observations from animal models

email: abarber@psu.edu have now been corroborated by clinical evidence using in vivo imaging techniques as well as by histological analysis of postmortem specimens. But there is also evidence that neurodegeneration is a process that involves more than the premature death of neurons, and is likely to include biochemical and morphological changes within neurons and their supporting glial cells. It may be that the functional abnormalities that are well documented to occur in DR are due to earlier alterations in the neural tissue and may precede the ultimate elimination of neurons by apoptosis or other forms of cell death. This review will consider some of the more recent data on retinal disease in diabetes, including neurodegeneration and functional deficits that lead to vision loss.

\section{Diabetes induces apoptosis and cell loss in the retina}

During the course of research on DR there have been many 
histological studies to examine its complex pathology. Early studies characterized the vascular lesions that were detected in post mortem specimens and fundus examination [3-5]. DR is still usually diagnosed by visual identification of a variety of vascular lesions such as microaneurysms and lipid deposits during the fundus exam, and include the functional breakdown of the blood retinal barrier leading to macular edema [6]. But early pathology studies also identified features of cell death and degeneration in retinal tissue from humans with diabetes [7,8]. Since degenerative features in neural tissue could not be visually detected during the fundus exam they did not contribute to characterization or diagnosis of the disease. Further animal studies demonstrated that experimental diabetes increased apoptotic cell death in the vasculature, using the trypsin digest technique to isolate the vascular network and then identify apoptotic cells by dUTP nick end labeling (TUNEL) [9]. Another histological study examined the entire neural retina as a flat-mount specimen, also stained by TUNEL [10]. This later approach enabled quantification of the total number of TUNEL-positive nuclei in each rat retina. The data showed that there were significantly more apoptotic cells in the retinas of diabetic rats compared to age-matched controls, even in rats that had been diabetic for only one month. The actual number of TUNEL-positive cells in each retina was quite small, however, ranging between 60 and 120 cells in a standardized area of $0.5 \mathrm{~cm}^{2}$, but the number of apoptotic cells remained similar in groups of rats that were diabetic for 1, 3, 6 and 12 months. These data suggested that while diabetes increased the rate of cell death in the retina, it was the result of a chronic degenerative process that began within weeks after the onset of hyperglycemia. This study also reported that the thickness of the inner plexiform and inner nuclear layers of retinas from rats that were diabetic for 7.5 months were also significantly reduced (by $22 \%$ and $14 \%$, respectively), again suggesting that the chronic loss of cells resulted in degeneration of neurons in the inner layers of the retina. The data also showed a significant reduction in the number of retinal ganglion cell bodies.

Other studies confirmed the increase in apoptosis using TUNEL labeling on whole retinas. It was shown that chronically elevated intraocular pressure augmented the diabetes-induced TUNEL-positive cell count [11]. The increase in TUNEL-positive cells, loss of retinal ganglion cells, and thinning of the inner retina were confirmed in streptozotocin-diabetic mice after 14 weeks of hyperglycemia [12], as well as the Ins $2^{\text {Akita }}$ mouse, which is a spontaneously diabetic model [13], and in the KKAY mouse, which is thought to model Type II diabetes [14].

There has been some degree of variation in the results of studies on retinal apoptosis in animal models of diabetes. Some cases report a more dramatic increase in apoptosis, and one study reported a dramatic loss of the photoreceptors after 24 weeks of streptozotocin-diabetes [15], but this result has not been confirmed and is unlikely to model the clinical condition. In contrast, a study on diabetic mice yielded negative findings on apoptosis and loss of neurons [16], but for the most part the consensus appears to be that experimental diabetes in rodents leads to neuronal apoptosis, loss of retinal ganglion cells and reduction in the thickness of the inner retina $[17,18]$.

\section{The retinal cell death involves several types of neurons}

Immunohistochemical work on retinas from diabetic animal models extended the concept that many of the cells undergoing apoptosis were subtypes of neurons, including retinal ganglion cells and amacrine cells. Immunohistochemistry was performed for CM-1, a marker for the activated form of caspase-3, which only appears in cells undergoing apoptosis. The study revealed a similar magnitude increase in CM-1 positive cells compared to that measured by TUNEL [1]. Many of the CM-1 positive cells appeared spatially distinct from blood vessels, which were identified by immunoreactivity for a vascular basement membrane protein called agrin, which is abundant in the retinal vasculature [19]. These data suggested that CM-1 positive cells were more likely to be neurons or glial cells undergoing apoptosis, rather than vascular cells (Figure 1). The CM-1 signal was colocalized with markers such as choline acetyl transferase and tyrosine hydroxylase in some cells, indicating cholinergic and dopaminergic amacrine cells; as well as NeuN, a ubiquitous marker of neurons. This study also found that the number of cholinergic and dopaminergic amacrine cells was depleted (by $20 \%$ and 16\%, respectively) in diabetic Ins $2^{\text {Akita }}$ mice after 6 months of hyperglycemia. An immunohistochemistry study on human postmortem tissue also identified caspase-3, Fas ligand and Bcl-2 in the nerve fiber layer and retinal ganglion cells, confirming that the loss of specific neurons by apoptosis also occurs in human diabetes [20]. The observed loss of amacrine neurons in diabetic rodents was extended recently by a study showing reduced levels of retinal dopamine after short durations of hyperglycemia in both rats and mice [21], suggesting that there is a loss of dopaminergic amacrine cells.

In summary, it appears that diabetes increases the cell death of neurons in the inner retina including retinal ganglion cells and both dopaminergic and cholinergic amacrine cells, and the cell death has been identified in both animal models and in human samples. It is likely that there is also accelerated cell death of bipolar cells and some photoreceptors. The interdependence and timing of apoptosis in the different neuronal populations is unknown and will be difficult to establish using traditional histological technology because of the low frequency of cell death events. Also the clinical significance of cell death in DR, especially during the early stages of the disease is still debated; however, the data now strongly support that apoptosis of retinal neurons 


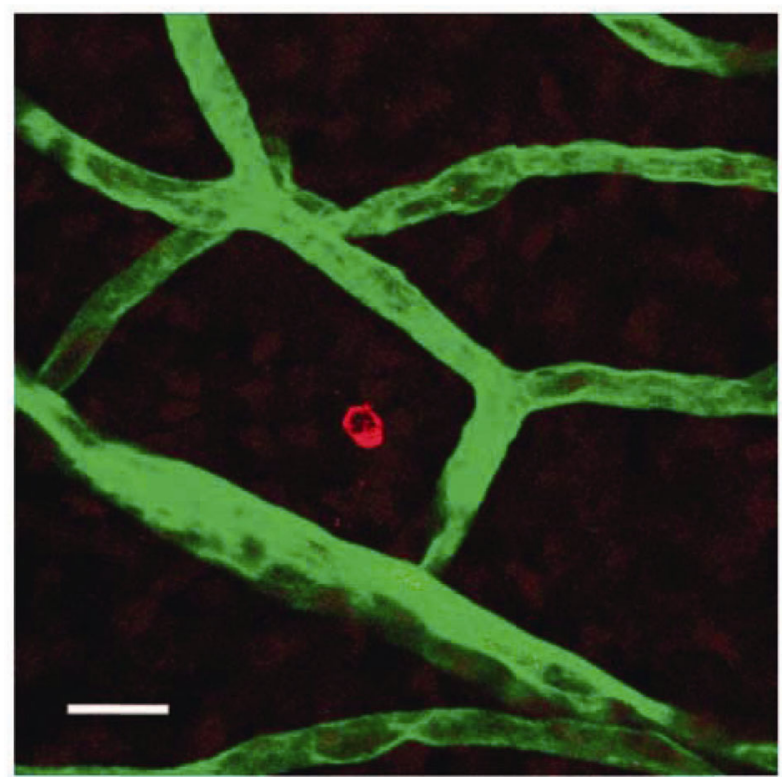

Figure 1 Apoptosis of non-vascular cells in retina from STZ-diabetic rats. Flat-mount retinas from STZ-diabetic and control rats were labeled for the active form caspase-3 (red) and the vascular basement membrane glycoprotein, agrin (green) and imaged by confocal microscopy. The image shows a typical caspase- 3 positive cell spatially distinct from agrin immunoreactivity on the retinal vasculature, indicating that the cell undergoing apoptosis was more likely to have neural rather than vascular origin. Scale bar, $50 \mu \mathrm{m}$. (Taken from [1])

is accelerated by diabetes and the onset of the increase in cell death is early in the time course of DR.

\section{In vivo imaging of retinal morphology con- firms early loss of neurons from the inner retina}

Several recent clinical studies have used in vivo imaging techniques to demonstrate thinning of the retinal nerve fiber layer in diabetes, often in patients with little or no evidence of vascular retinopathy. Scanning laser polarimetry established that the thickness of the retinal nerve fiber layer was significantly reduced in a small group of type 1 diabetic patients without retinopathy or other microvascular complications [22]. A larger study using the same approach also reported thinning in the nerve fiber layer [23]. A more extensive study on a population of patients with Type II diabetes, screened to exclude glaucoma, confirmed the thinning of the retinal nerve fiber layer [24]. These studies strongly suggest that there is a gradual loss of retinal ganglion cells in diabetic patients.

Recently there has been a wide expansion of the use of optical coherence tomography (OCT) in clinical diagnosis and research on retinal diseases. OCT has been used to measure subtle changes in the thickness of retinal cell layers of people with diabetes, at the very early stages of vascular retinopathy. An OCT study of a small number of patients with Type II diabetes discovered a significant thinning of the nerve fiber layer in the superior quadrants of the retina [25]. A further OCT study measured the pericentral retinal thickness of patients with Type I diabetes compared to healthy controls. The results revealed a statistically significant retinal thinning of the pericentral area around the fovea in diabetic patients with minimal DR, compared to the healthy control group [26]. While the retinal thickness of the diabetic patients was only about $5 \%$ less than that of the healthy subjects, the results indicated a potential early loss of axonal tissue in an important region of the macula, presumably indicating a degeneration affecting retinal ganglion cells. A study of a mixed population of Type I and Type II diabetic patients showed that the thinning of the nerve fiber layer was correlated with fasting blood glucose levels [27]. Again it is important to note that the selected population had only pre-clinical retinopathy, suggesting that these degenerative changes could be detected at an earlier time point than major vascular lesions. A similar but higher resolution study on diabetic patients who also had minimal retinopathy found a differential reduction in the thickness of the combined ganglion cell and inner plexiform layer (by $2.7 \mu \mathrm{m}$ ), and a smaller loss of the inner nuclear layer compared to healthy age-matched controls [28]. The reductions were again limited to the pericentral region of the macula, while more peripheral regions of retina were not altered. A follow up study by the same investigators reported even greater loss of tissue thickness in the pericentral ganglion cell layer $(5.1 \mu \mathrm{m})$ and also a loss in the peripheral macula nerve fiber layer $(3.7 \mu \mathrm{m})$ of patients with Type I diabetes and minimal vascular retinopathy [29]. This study also found a significant correlation between ganglion cell layer thickness and the duration of diabetes. The same research group also established that there were similar changes in retinal thickness in a group of Type II diabetic patients [30]. A more recent study of patients with no clinically detectible macular edema again reported a significant reduction in the thickness of the retinal nerve fiber layer in patients with diabetes, while there was also a significant increase in the thickness of the inner plexiform and nuclear layers [31]. The authors suggested that the unprecedented increase in thickness of the inner retina layers may have been due to Müller cell inflammation and swelling, rather than edema, which had not been detected during fundus examination. It should also be noted that two OCT studies identified sex differences in the macular thickness and nerve fiber layer in patients with diabetes, so future clinical studies using this approach may be required to differentiate between data from males and females [32,33].

The reduction in retina thickness measured by OCT is relatively small. But this small loss of inner retina tissue may have clinical relevance because some studies have demonstrated correlations with functional measures of vision. One study showed that macular and foveal thickness was negatively correlated with duration of diabetes [34], 
suggesting that the loss of thickness is progressive, and this was confirmed more recently [35]. Thinning of the nerve fiber layer was also detected in adolescents with Type II diabetes, along with reductions in the electroretinogram and venular dilation, showing that the structural changes in retinal thickness are accompanied by loss of neural and vascular function [36]. Another study found that the ganglion cell layer thickness was a significant predictor of decreased visual function measured by the Rarebit perimetry and fovea test, which can be used to detect subtle defects in function [37,38].

There has been a rapid increase in OCT usage in clinical research, which has validated the observations of inner retina degeneration in the diabetic animal models. Reductions in the thickness of the nerve fiber layer are most likely to indicate a reduced abundance of retinal ganglion cell axons, and presumably a loss of the cell bodies and dendrites. This deficit is likely to limit the ability to transmit visual information to the brain and compromise the information processing capacity of the inner retina. In most studies the nerve fiber layer loss was apparent in a population of patients that did not have macular edema, suggesting that significant neural degeneration occurred before a clinically apparent loss of vascular barrier function.

\section{OCT imaging identifies retinal thickness changes in animal models of diabetes}

There have been fewer studies using OCT in animal models of diabetes compared to the clinical research. But with the increase in availability of OCT devices adapted for animals it seems likely that this will soon change. Recent data from animal models appear to reflect the clinical observations. A study of leptin-deficient mice, which are thought to model obesity and Type II diabetes, used OCT imaging to show a significant reduction in the combined thickness of the nerve fiber and inner plexiform layers in mice that were 22 weeks old [39]. OCT was also used to establish a significant reduction in the thickness of the retinal nerve fiber layer and total retinal thickness in Otuska Long-Evans Tokushima fatty rats, which also model Type II diabetes [40]. A study on the Ins $2^{\text {Akita }}$ mouse reported no significant changes in retinal thickness using OCT and histology [41], despite earlier histological studies showing a significant reduction in the thickness of the inner layers of the Ins $2^{\text {Akita }}$ retina [13]. A further OCT study, however, reported that Ins $2^{\text {Akita }}$ diabetic mice did have a progressive thinning of the inner retina which became apparent 3 months after the onset of hyperglycemia [42]. It seems likely that the Ins $2^{\text {Akita }}$ model shows variability between different colonies, and may be a less reliable model compared to the streptozotocin-diabetic rodents.

The current consensus appears to be that OCT is a valid approach that is sensitive enough to detect reductions in the thickness of the inner retina in rodent models of diabetes. With the expanding availability of OCT devices adapted for rodent imaging it is likely that in vivo measures of retinal thinning will become more common in basic and translational research studies. This will offer a valuable method to confirm significant retinal neurodegeneration, and potential protection of tissue in translational studies, before the animals are sacrificed for biochemical or histological analysis.

\section{Degenerative changes in synapses and neuron morphology accompany cell death}

In the previous histological studies that measured reductions in the thickness of the cell layers of the retina the greatest change was in the thickness of the inner plexiform layer, accompanied by a smaller reduction in the thickness of the inner nuclear layer $[10,13]$. One explanation for these reductions is that a cumulative loss of amacrine or bipolar cells by apoptosis caused the reduction in tissue volume [1], but the loss of the inner plexiform layer suggests that there was also an accompanying reduction on the volume of dendrites and synaptic connections. To test this possibility the retinas of diabetic rats were labeled by immunofluorescence for several protein markers of synapses, including synaptophysin, which is an abundant presynaptic vesicle protein in retina and brain [43]. The results demonstrated that the protein content of synaptophysin and several other synaptic proteins was significantly reduced after 1 and 3 months of streptozotocin-induced diabetes in rats. Similar results were obtained from the hippocampus a well as retinas of diabetic rats, supporting the possibility that diabetes may alter synaptic protein regulation in the brain and other parts of the nervous system as well as the retina [44]. The reduction in synaptic marker proteins was ameliorated by correcting diabetes with insulin if the treatment was initiated after a short period of diabetes, but not after a more protracted period, suggesting that after longer durations of hyperglycemia the changes in synapse number or synaptic protein content are irreversible [45]. Blockade of the angiotensin II type 1 receptor also protected diabetic rats against the loss of synaptophysin [46], as did high doses of lutein in diabetic mice, indicating some potential mechanisms [47].

The significant reductions in synaptic protein content occurred soon after the onset of diabetes and cannot be fully explained by loss of a small number of neurons, suggesting that these degenerative changes may be a precursor to neuronal cell death. Further work used ${ }^{35}$ S-labeling of explant retinas from diabetic and control rats to determine changes in the synthesis of synaptophysin [48]. The work suggested that abnormal mRNA translation and post-translational mannosylation was responsible for the reduced content of mature synaptophysin protein. It is possible that early dysregulation of synaptophysin synthesis, and possibly other synaptic proteins, could compromise neurotransmission 
efficiency leading to an inadequacy in neuron-neuron communication required for visual information processing.

As well as alterations in presynaptic protein regulation, diabetes may result in altered neuronal morphology, especially in retinal ganglion cells. One study labelled retinal ganglion cells with DiI delivered by gene gun, and found that some retinal ganglion cells of diabetic rats had enlarged dendritic fields [49]. Another study used the Ins $2^{\text {Akita }}$ mice crossed with Thy1-YFP mice, which express yellow fluorescent protein throughout the entire structure of a random subset of retinal ganglion cells. Confocal microscopy revealed a number of pathological characteristics in these cells including cell body swelling and axonal varicosities associated with thinning [2]. There was also a significant increase in the density of dendrites in large ON-ganglion cells, measured by Scholl analysis (Figure 2). Similar pathological features were also described in a small study using DiI on postmortem human retinas [50]. The small amount of morphological data that is available suggests that diabetes leads to changes in the dendrite morphology of retinal ganglion cells, possibly as a precursor to cell death, and also appears to alter the content of certain synaptic proteins. The data suggest that there is either a reduction in the number of synapses or a change in synaptic protein synthesis and turnover, accompanied by alterations in dendrite morphology which could be compensatory to reductions in synaptic input. It seems likely that these morphological and protein regulatory deficits have the potential to compromise the functional output of the retina in a way that will influence vision.

\section{The scotopic threshold response as a measure of visual function in diabetes}

One of the more recent trends in diabetic retinopathy re-
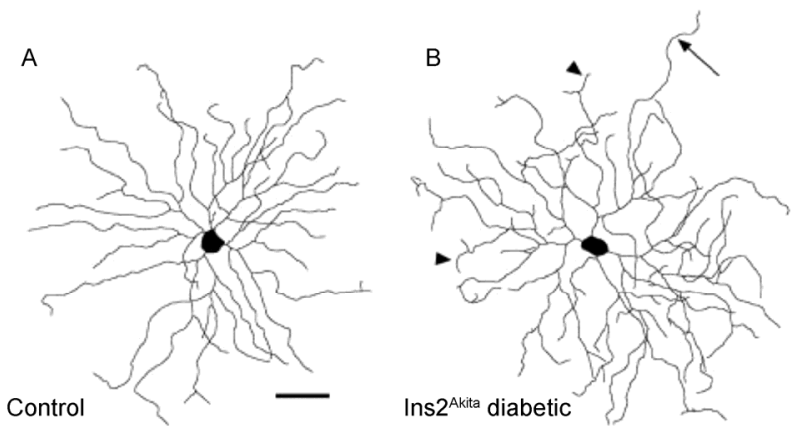

Figure 2 Retinal ganglion cell morphology in diabetic Ins2 ${ }^{\text {Akita }}$ mice. Ins $2^{\text {Akita }}$ and Thy1-YFP mice were crossed to reveal the retinal ganglion cell morphology. Whole mount retinas were imaged by confocal microscopy to create line maps of individual retinal ganglion cells. A, A typical $\mathrm{ON}$-ganglion cell from a wild-type mouse retina. B, ON-ganglion cell from a diabetic Ins $2^{\text {Akita/+ }}$ mouse showing dendrites with many small terminals (arrowheads), and occasional long unbranched dendrites extending beyond the normal dendritic arbor (arrow). Scale bar, $50 \mu \mathrm{m}$. (Taken from [2]). search has been an increased emphasis on functional assessment of vision. Advances in electrophysiological recording equipment have enabled animal research with increased clinical relevance, because the electrophysiological response in animals appears to closely reflect the observations in humans. Subtle alterations in the electroretinogram in patients with diabetes have been established for many years [51-53] and similar changes are found in animal models. Typically the b-wave amplitude is reduced while the oscillatory potentials are delayed and also reduced in amplitude [54-58]. While the changes in the ERG waveform are well established, it has been difficult to interpret what cellular and molecular mechanisms could be responsible for the deficits because the standard ERG is a composite signal derived from the combination of cell populations across the entire retina. The scotopic threshold response (STR) represents a more selective electrophysiological measure compared to the ERG because it is thought to be derived from the inner retina and is the result of very low intensity light flashes $[59,60]$. It has both positive and negative wave components, which are likely derived from retinal ganglion cells with a possible contribution from amacrine cells in the inner retina because it can be partially abolished by optic nerve transection leading to selective ganglion cell death [61].

An early clinical study established that the amplitude of the STR was reduced in humans with diabetes [62,63]. More recently this observation was confirmed in rats and mice with diabetes. The positive STR amplitude was reduced by $51 \%$ in rats after only 4 weeks of streptozotocin-diabetes, and this deficit preceded significant changes in other ERG components [56]. Similarly, diabetic Ins $2^{\text {Akita }}$ mice had a reduced STR amplitude after 6 weeks of hyperglycemia [64]. When non-opioid sigma receptor 1 knockout mice were made diabetic, the reduction in the STR was greater than that in diabetic wild-type mice, and the diabetic knockout mice also had fewer surviving retinal ganglion cells, suggesting that the reduced STR is related to accelerated RGC death [65]. A study on rats suggested that the reduction in STR ganglion cell function correlated with increases in connective tissue growth factor and the TGF $\beta$ receptor, rather than gross morphological changes in the inner retina and optic nerve [66].

The STR is generally considered more difficult to measure than the standard ERG because its amplitude is small and is a response to very low intensity stimuli. Measuring the STR requires extensive dark adaptation as well as extensive response averaging. Introduction of modern electrophysiology equipment, however, has made this approach more practicable; especially in animals because they can be dark adapted over several hours and are anesthetized during recording. The ERG has been used extensively to measure retinal function in rodent models of diabetes but there are opportunities such as the STR and other electrophysiological paradigms to reveal mechanistic information about more 
specific functional deficits in diabetes.

\section{Measurement of visual function using opto- kinetic behavior in animal models of diabetes}

The introduction of equipment to accurately measure the optokinetic response of rodents [67] has enabled measures of deficits in spatial frequency threshold and contrast sensitivity in animal models of diabetes. An initial study showed that diabetic Long-Evans rats had significant optokinetic defects after 4 weeks of hyperglycemia [68]. The visual deficits were also identified in the Ins $2^{\text {Akita }}$ mouse but appear to progress at a slower rate compared to rats [69-71]. The loss of visual function in streptozotocin-diabetic LongEvans rats became significant after 1 month of hyperglycemia and correlated with ERG implicit times, although these changes also correlated with lens opacity in animals with longer durations of diabetes [58]. Part of the early deficit in visual function may, however, be due to loss of dopamine signaling, since the reductions in optokinetic behavior and ERG were prevented by therapy with L-DOPA [21]. Also, diabetic mice with a knock out for aldose reductase did not have the visual function deficit [72]. Furthermore, reduction of the oxidative stress response through mutation of the transcription factor, Nrf2, also worsened the optokinetic visual function in diabetic mice, suggesting that super oxide production can worsen vision loss in diabetes [73].

\section{Functional changes in neuro-vascular cou- pling}

Compromised vascular function is synonymous with DR. The loss of integrity of the inner blood-retinal barrier is well established and the primary cause of macular edema [74]. It is thought that this is due in part to dysregulation of the vascular endothelial tight junction proteins that are responsible for creating the permeability barrier $[75,76]$. Recently there has been documentation of other functional changes in retinal neuro-vascular coupling that may occur early in diabetes [77]. One study used a dynamic retinal vessel analyzer to measure real-time changes in the caliber of large retinal vessels in response to metabolic challenges induced by flickering light or hyperoxia. The results indicated that patients with Type II diabetes had an impaired arterial vasodilator and vasoconstrictor response. The impairment did not correlate with blood glucose or insulin levels, suggesting that the mechanism was not dependent on the acute diabetic state [78]. A further study found similar results in a clinical population with pre-diabetes, defined as $\mathrm{HbA} 1 \mathrm{C}$ between $5.7 \%$ and $6.5 \%$. The deficit in the pre-diabetic populations was similar to that of the diabetic population with $\mathrm{HbA} 1 \mathrm{C}$ above $6.5 \%$, suggesting that this is an early event in the course of DR and could represent a sensitive predictive measure [79]. Another recent study suggested that retinal neurovascular coupling is influenced by blood glucose because improving glycemic control with the dipeptidyl peptidase-4 inhibitor, saxagliptin, also improved retinal hemodynamics in patients with Type II diabetes [80]. This early change in neurovascular function may also occur in the absence of detectible changes in electrophysiological function measured by multifocal ERG, suggesting that it is independent of neuronal deficits [81]. Other data, however, show that multifocal ERG deficits can be predictive of the appearance of vascular lesions occurring within 2-3 years $[82,83]$. Neurovascular coupling is the result of a functional relationship between vascular and neural cells. Diabetes leads to a breakdown in this relationship, causing a failure of the vasculature to respond appropriately to the local metabolic demand of the neural tissue. While the mechanisms for these deficits are poorly understood, changes in neurovascular coupling may represent an early predictor for DR.

\section{Conclusion}

DR is a disease with a complex and progressive pathology [84]. Early in the progress of the disease there are changes in the vascular and neural components of the tissue leading to abnormal neurovascular coupling [78,79]. Although it is unclear if functional changes in the vasculature are pathological or compensatory, they may represent a method for early diagnosis of the disease. There are also subtle but measurable deficits in visual function that may become predictors of disease progression after more research [64,85-88].

The underlying mechanisms of retinal neurodegeneration in DR are still unclear. It is still not known if the neuropathy that is now well established to occur in the retina is associated with or independent of the development of microvascular disease, but understanding the early alterations in the neural component of the retina may offer greater opportunities for early diagnosis and treatment. The biochemical changes that precede cell death are more likely to be reversible with pharmacological intervention. Thus the best hope for developing the successful preventive medicines of the future will be through further research into the early mechanisms of retinal degeneration in diabetes. This work must include an increasing emphasis on methods to assess the early deficits in visual function. Our goal should be to develop better methods for early detection of DR as well as new preventive therapies.

The author acknowledges past funding from the Juvenile Diabetes Research Foundation International, the American Diabetes Association, the Pennsylvania Lions Sight Conservation and Eye Research Foundation, and Fight for Sight. 
1 Gastinger MJ, Singh RS, Barber AJ. Loss of cholinergic and dopaminergic amacrine cells in streptozotocin-diabetic rat and ins2akita-diabetic mouse retinas. Invest Ophthalmol Vis Sci, 2006, 47: 3143-3150

2 Gastinger MJ, Kunselman AR, Conboy EE, Bronson SK, Barber AJ. Dendrite remodeling and other abnormalities in the retinal ganglion cells of ins 2 akita diabetic mice. Invest Ophthalmol Vis Sci, 2008, 49: 2635-2642

3 Bloodworth JM Jr., Molitor DL. Ultrastructural aspects of human and canine diabetic retinopathy. Invest Ophthalmol, 1965, 4: 1037-1048

4 Bloodworth JM Jr. Diabetic microangiopathy. Diabetes, 1963, 12: 99-114

5 Cunha-Vaz JG. Pathophysiology of diabetic retinopathy. British J Ophthalmol, 1978, 62: 351-355

6 Cunha-Vaz JG. Studies on the pathophysiology of diabetic retinopathy. The blood-retinal barrier in diabetes. Diabetes, 1983, 32(Suppl 2): 20-27

7 Bloodworth JM Jr. Diabetic retinopathy. Diabetes, 1962, 11: 1-22

8 Wolter JR. Diabetic retinopathy. Am J Ophthalmol, 1961, 51: 1123-1139

9 Mizutani M, Kern TS, Lorenzi M. Accelerated death of retinal microvascular cells in human and experimental diabetic retinopathy. $\mathrm{J}$ Clin Invest, 1996, 97: 2883-2890

10 Barber AJ, Lieth E, Khin SA, Antonetti DA, Buchanan AG, Gardner TW. Neural apoptosis in the retina during experimental and human diabetes. Early onset and effect of insulin. J Clin Invest, 1998, 102: 783-791

11 Kanamori A, Nakamura M, Mukuno H, Maeda H, Negi A. Diabetes has an additive effect on neural apoptosis in rat retina with chronically elevated intraocular pressure. Curr Eye Res, 2004, 28: 47-54

12 Martin PM, Roon P, Van Ells TK, Ganapathy V, Smith SB. Death of retinal neurons in streptozotocin-induced diabetic mice. Invest Ophthalmol Vis Sci, 2004, 45: 3330-3336

13 Barber AJ, Antonetti DA, Kern TS, Reiter CE, Soans RS, Krady JK, Levison SW, Gardner TW, Bronson SK. The ins2akita mouse as a model of early retinal complications in diabetes. Invest Ophthalmol Vis Sci, 2005, 46: 2210-2218

14 Ning X, Baoyu Q, Yuzhen L, Shuli S, Reed E, Li QQ. Neuro-optic cell apoptosis and microangiopathy in kkay mouse retina. Int $\mathrm{J}$ Mol Med, 2004, 13: 87-92

15 Park SH, Park JW, Park SJ, Kim KY, Chung JW, Chun MH, Oh SJ. Apoptotic death of photoreceptors in the streptozotocin-induced diabetic rat retina. Diabetologia, 2003, 46: 1260-1268

16 Feit-Leichman RA, Kinouchi R, Takeda M, Fan Z, Mohr S, Kern TS, Chen DF. Vascular damage in a mouse model of diabetic retinopathy: relation to neuronal and glial changes. Invest Ophthalmol Vis Sci, 2005, 46: 4281-4287

17 Barber AJ. A new view of diabetic retinopathy: a neurodegenerative disease of the eye. Prog Neuro-Psychopharmacol Biol Psychiatry, 2003, 27: 283-290

18 Barber AJ, Gardner TW, Abcouwer SF. The significance of vascular and neural apoptosis to the pathology of diabetic retinopathy. Invest Ophthalmol Vis Sci, 2011, 52: 1156-1163

19 Barber AJ, Lieth E. Agrin accumulates in the brain microvascular basal lamina during development of the blood-brain barrier. Dev Dyn, 1997, 208: 62-74

20 Abu-El-Asrar AM, Dralands L, Missotten L, Al-Jadaan IA, Geboes K. Expression of apoptosis markers in the retinas of human subjects with diabetes. Invest Ophthalmol Vis Sci, 2004, 45: 2760-2766

21 Aung MH, Park HN, Han MK, Obertone TS, Abey J, Aseem F, Thule PM, Iuvone PM, Pardue MT. Dopamine deficiency contributes to early visual dysfunction in a rodent model of type 1 diabetes. J Neurosci, 2014, 34: 726-736

22 Lopes de Faria JM, Russ H, Costa VP. Retinal nerve fibre layer loss in patients with type 1 diabetes mellitus without retinopathy. British J Ophthalmol, 2002, 86: 725-728

23 Ozdek S, Lonneville YH, Onol M, Yetkin I, Hasanreisoglu BB. Assessment of nerve fiber layer in diabetic patients with scanning laser polarimetry. Eye (London, England), 2002, 16: 761-765

24 Takahashi H, Goto T, Shoji T, Tanito M, Park M, Chihara E. Diabetes-associated retinal nerve fiber damage evaluated with scanning laser polarimetry. Am J Ophthalmol, 2006, 142: 88-94

25 Sugimoto M, Sasoh M, Ido M, Wakitani Y, Takahashi C, Uji Y. Detection of early diabetic change with optical coherence tomography in type 2 diabetes mellitus patients without retinopathy. Ophthalmologica, 2005, 219: 379-385

26 Biallosterski C, van Velthoven ME, Michels RP, Schlingemann RO, DeVries JH, Verbraak FD. Decreased optical coherence tomographymeasured pericentral retinal thickness in patients with diabetes mellitus type 1 with minimal diabetic retinopathy. British $\mathbf{J}$ Ophthalmol, 2007, 91: 1135-1138

27 Peng PH, Lin HS, Lin S. Nerve fibre layer thinning in patients with preclinical retinopathy. Can J Ophthalmol, 2009, 44: 417-422

28 van Dijk HW, Kok PHB, Garvin M, Sonka M, Devries JH, Michels RPJ, van Velthoven MEJ, Schlingemann RO, Verbraak FD, Abramoff MD. Selective loss of inner retinal layer thickness in type 1 diabetic patients with minimal diabetic retinopathy. Invest Ophthalmol Vis Sci, 2009, 50: 3404-3409

29 van Dijk HW, Verbraak FD, Kok PH, Garvin MK, Sonka M, Lee K, Devries JH, Michels RP, van Velthoven ME, Schlingemann RO, Abramoff MD. Decreased retinal ganglion cell layer thickness in patients with type 1 diabetes. Invest Ophthalmol Vis Sci, 2010, 51: 3660-3665

30 van Dijk HW, Verbraak FD, Kok PH, Stehouwer M, Garvin MK, Sonka M, DeVries JH, Schlingemann RO, Abramoff MD. Early neurodegeneration in the retina of type 2 diabetic patients. Invest Ophthalmol Vis Sci, 2012, 53: 2715-2719

31 Vujosevic S, Midena E. Retinal layers changes in human preclinical and early clinical diabetic retinopathy support early retinal neuronal and muller cells alterations. J Diabetes Res, 2013, 2013: 905058

32 Oshitari T, Hanawa K, Adachi-Usami E. Changes of macular and rnfl thicknesses measured by stratus oct in patients with early stage diabetes. Eye (London, England), 2009, 23: 884-889

33 Browning DJ, Fraser CM, Clark S. The relationship of macular thickness to clinically graded diabetic retinopathy severity in eyes without clinically detected diabetic macular edema. Ophthalmology, 2008, 115: 533-539.e532

34 Asefzadeh B, Fisch BM, Parenteau CE, Cavallerano AA. Macular thickness and systemic markers for diabetes in individuals with no or mild diabetic retinopathy. Clin Exp Ophthalmol, 2008, 36: 455-463

35 Araszkiewicz A, Zozulinska-Ziolkiewicz D, Meller M, BernardczykMeller J, Pilacinski S, Rogowicz-Frontczak A, Naskret D, WieruszWysocka B. Neurodegeneration of the retina in type 1 diabetic patients. Pol Arch Med Wewn, 2012, 122: 464-470

36 Bronson-Castain KW, Bearse MA, Jr., Neuville J, Jonasdottir S, King-Hooper B, Barez S, Schneck ME, Adams AJ. Adolescents with type 2 diabetes: Early indications of focal retinal neuropathy, retinal thinning, and venular dilation. Retina, 2009, 29: 618-626

37 van Dijk HW, Verbraak FD, Stehouwer M, Kok PH, Garvin MK, Sonka M, DeVries JH, Schlingemann RO, Abramoff MD. Association of visual function and ganglion cell layer thickness in patients with diabetes mellitus type 1 and no or minimal diabetic retinopathy. Vis Res, 2011, 51: 224-228

38 Frisen L. New, sensitive window on abnormal spatial vision: rarebit probing. Vis Res, 2002, 42: 1931-1939

39 Zhi Z, Chao JR, Wietecha T, Hudkins KL, Alpers CE, Wang RK. Noninvasive imaging of retinal morphology and microvasculature in obese mice using optical coherence tomography and optical microangiography. Invest Ophthalmol Vis Sci, 2014, 55: 1024-1030

40 Yang JH, Kwak HW, Kim TG, Han J, Moon SW, Yu SY. Retinal neurodegeneration in type ii diabetic otsuka long-evans tokushima fatty rats. Invest Ophthalmol Vis Sci, 2013, 54: 3844-3851

41 McLenachan S, Chen X, McMenamin PG, Rakoczy EP. Absence of clinical correlates of diabetic retinopathy in the ins2akita retina. Clin Exp Ophthalmol, 2013, 41: 582-592

42 Hombrebueno JR, Chen M, Penalva RG, Xu H. Loss of synaptic connectivity, particularly in second order neurons is a key feature of 
diabetic retinal neuropathy in the ins2akita mouse. PLoS One, 2014, 9: e97970

43 VanGuilder HD, Brucklacher RM, Patel K, Ellis RW, Freeman WM, Barber AJ. Diabetes downregulates presynaptic proteins and reduces basal synapsin i phosphorylation in rat retina. Eur J Neurosci, 2008, 28: $1-11$

44 Gaspar JM, Baptista FI, Galvao J, Castilho AF, Cunha RA, Ambrosio AF. Diabetes differentially affects the content of exocytotic proteins in hippocampal and retinal nerve terminals. Neuroscience, 2010, 169: $1589-1600$

45 Masser DR, VanGuilder Starkey HD, Bixler GV, Dunton W, Bronson SK, Freeman WM. Insulin treatment normalizes retinal neuroinflammation but not markers of synapse loss in diabetic rats. Exp Eye Res, 2014, 125: 95-106

46 Kurihara T, Ozawa Y, Nagai N, Shinoda K, Noda K, Imamura Y, Tsubota K, Okano H, Oike Y, Ishida S. Angiotensin II type 1 receptor signaling contributes to synaptophysin degradation and neuronal dysfunction in the diabetic retina. Diabetes, 2008, 57: 2191-2198

47 Sasaki M, Ozawa Y, Kurihara T, Kubota S, Yuki K, Noda K, Kobayashi S, Ishida S, Tsubota K. Neurodegenerative influence of oxidative stress in the retina of a murine model of diabetes. Diabetologia, 2010, 53: 971-979

48 D'Cruz TS, Weibley BN, Kimball SR, Barber AJ. Post-translational processing of synaptophysin in the rat retina is disrupted by diabetes. PLoS One, 2012, 7: e44711

49 Qin Y, Xu G, Wang W. Dendritic abnormalities in retinal ganglion cells of three-month diabetic rats. Curr Eye Res, 2006, 31: 967-974

50 Meyer-Rusenberg B, Pavlidis M, Stupp T, Thanos S, MeyerRusenberg B, Pavlidis M, Stupp T, Thanos S. Pathological changes in human retinal ganglion cells associated with diabetic and hypertensive retinopathy. Graefes Arch Clin Exp Ophthalmol, 2007, 245: 1009-1018

51 Simonsen SE. Prognostic value of erg (oscillatory potential) in juvenile diabetics. Acta Ophthalmol Suppl, 1974, 123: 223-224

52 Frost-Larsen K, Larsen HW, Simonsen SE. Oscillatory potential and nyctometry in insulin-dependent diabetics. Acta Ophthalmol (Copenh), 1980, 58: 879-888

53 Simonsen SE. The value of the oscillatory potential in selecting juvenile diabetics at risk of developing proliferative retinopathy. Acta Ophthalmol (Copenh), 1980, 58: 865-878

54 Li Q, Zemel E, Miller B, Perlman I. Early retinal damage in experimental diabetes: electroretinographical and morphological observations. Exp Eye Res, 2002, 74: 615-625

55 Shinoda K, Rejdak R, Schuettauf F, Blatsios G, Volker M, Tanimoto N, Olcay T, Gekeler F, Lehaci C, Naskar R, Zagorski Z, Zrenner E. Early electroretinographic features of streptozotocin-induced diabetic retinopathy. Clin Exp Ophthalmol, 2007, 35: 847-854

56 Kohzaki K, Vingrys AJ, Bui BV, Kohzaki K, Vingrys AJ, Bui BV. Early inner retinal dysfunction in streptozotocin-induced diabetic rats. Invest Ophthalmol Vis Sci, 2008, 49: 3595-3604

57 Hancock HA, Kraft TW. Oscillatory potential analysis and ergs of normal and diabetic rats. Invest Ophthalmol Vis Sci, 2004, 45: 1002-1008

58 Aung MH, Kim MK, Olson DE, Thule PM, Pardue MT. Early visual deficits in streptozotocin-induced diabetic long evans rats. Invest Ophthalmol Vis Sci, 2013, 54: 1370-1377

59 Bush RA, Hawks KW, Sieving PA. Preservation of inner retinal responses in the aged royal college of surgeons rat. Evidence against glutamate excitotoxicity in photoreceptor degeneration. Invest Ophthalmol Vis Sci, 1995, 36: 2054-2062

60 Sugawara T, Sieving PA, Iuvone PM, Bush RA. The melatonin antagonist luzindole protects retinal photoreceptors from light damage in the rat. Invest Ophthalmol Vis Sci, 1998, 39: 2458-2465

61 Bui BV, Fortune B. Ganglion cell contributions to the rat full-field electroretinogram. J Physiol, 2004, 555: 153-173

62 Abraham FA, Haimovitz J, Berezin M. The photopic and scotopic visual thresholds in diabetics without diabetic retinopathy. Metab Pediatr Syst Ophthalmol, 1988, 11: 76-77
63 Aylward GW, Billson FA. The scotopic threshold response in diabetic retinopathy - a preliminary report. Aus New Zealand J Ophthalmol, 1989, 17: 369-372

64 Nasralah Z, Robinson W, Jackson G, Barber A. Measuring visual function in diabetic retinopathy: progress in basic and clinical research. J Clin Exp Ophthalmol, 2013, 4: 1000306

65 Ha Y, Saul A, Tawfik A, Zorrilla EP, Ganapathy V, Smith SB. Diabetes accelerates retinal ganglion cell dysfunction in mice lacking sigma receptor 1. Mol Vis, 2012, 18: 2860-2870

66 Bui BV, Loeliger M, Thomas M, Vingrys AJ, Rees SM, Nguyen $\mathrm{CTO}, \mathrm{He} \mathrm{Z}$, Tolcos M. Investigating structural and biochemical correlates of ganglion cell dysfunction in streptozotocin-induced diabetic rats. Exp Eye Res, 2009, 88: 1076-1083

67 Prusky GT, Alam NM, Beekman S, Douglas RM. Rapid quantification of adult and developing mouse spatial vision using a virtual optomotor system. Invest Ophthalmol Vis Sci, 2004, 45: $4611-4616$

68 Kirwin SJ, Kanaly ST, Hansen CR, Cairns BJ, Ren M, Edelman JL. Retinal gene expression and visually evoked behavior in diabetic long evans rats. Invest Ophthalmol Vis Sci, 2011, 52: 7654-7663

69 Akimov NP, Renteria RC. Spatial frequency threshold and contrast sensitivity of an optomotor behavior are impaired in the ins2akita mouse model of diabetes. Behav Brain Res, 2012, 226: 601-605

70 Umino Y, Solessio E. Loss of scotopic contrast sensitivity in the optomotor response of diabetic mice. Invest Ophthalmol Vis Sci, 2013, 54: 1536-1543

71 Muir ER, Renteria RC, Duong TQ. Reduced ocular blood flow as an early indicator of diabetic retinopathy in a mouse model of diabetes. Invest Ophthalmol Vis Sci, 2012, 53: 6488-6494

72 Lee CA, Li G, Patel MD, Petrash JM, Benetz BA, Veenstra A, Amengual J, von Lintig J, Burant CJ, Tang J, Kern TS. Diabetesinduced impairment in visual function in mice: Contributions of $\mathrm{p} 38$ mapk, rage, leukocytes, and aldose reductase. Invest Ophthalmol Vis Sci, 2014, 55: 2904-2910

73 Xu Z, Wei Y, Gong J, Cho H, Park JK, Sung ER, Huang H, Wu L, Eberhart C, Handa JT, Du Y, Kern TS, Thimmulappa R, Barber AJ, Biswal S, Duh EJ. Nrf2 plays a protective role in diabetic retinopathy in mice. Diabetologia, 2014, 57: 204-213

74 Gardner TW, Antonetti DA, Barber AJ, LaNoue KF, Levison SW. Diabetic retinopathy: more than meets the eye. Survey Ophthalmol, 2002, 47: S253-262

75 Antonetti DA, Barber AJ, Khin S, Lieth E, Tarbell JM, Gardner TW. Vascular permeability in experimental diabetes is associated with reduced endothelial occludin content: vascular endothelial growth factor decreases occludin in retinal endothelial cells. Diabetes, 1998, 47: 1953-1959

76 Murakami T, Felinski EA, Antonetti DA. Occludin phosphorylation and ubiquitination regulate tight junction trafficking and vascular endothelial growth factor-induced permeability. J Biol Chem, 2009, 284: 21036-21046

77 Abcouwer SF, Gardner TW. Diabetic retinopathy: loss of neuroretinal adaptation to the diabetic metabolic environment. Ann New York Acad Sci, 2014, 1311: 174-190

78 Lott ME, Slocomb JE, Shivkumar V, Smith B, Gabbay RA, Quillen D, Gardner TW, Bettermann K. Comparison of retinal vasodilator and constrictor responses in type 2 diabetes. Acta Ophthalmol (Oxf), 2012, 90: e434-441

79 Lott ME, Slocomb JE, Shivkumar V, Smith B, Quillen D, Gabbay RA, Gardner TW, Bettermann K. Impaired retinal vasodilator responses in prediabetes and type 2 diabetes. Acta Ophthalmol (Oxf), 2013, 91: e462-469

80 Ott C, Raff U, Schmidt S, Kistner I, Friedrich S, Bramlage P, Harazny JM, Schmieder RE. Effects of saxagliptin on early microvascular changes in patients with type 2 diabetes. Cardiovasc Diabetol, 2014, 13: 19

81 Lasta M, Pemp B, Schmidl D, Boltz A, Kaya S, Palkovits S, Werkmeister R, Howorka K, Popa-Cherecheanu A, Garhofer G, Schmetterer L. Neurovascular dysfunction precedes neural dysfun- 
ction in the retina of patients with type 1 diabetes. Invest Ophthalmol Vis Sci, 2013, 54: 842-847

82 Bearse MA, Jr., Adams AJ, Han Y, Schneck ME, Ng J, BronsonCastain K, Barez S. A multifocal electroretinogram model predicting the development of diabetic retinopathy. Prog Retinal Eye Res, 2006, 25: 425-448

83 Ng JS, Bearse MA, Jr., Schneck ME, Barez S, Adams AJ. Local diabetic retinopathy prediction by multifocal erg delays over 3 years. Invest Ophthalmol Vis Sci, 2008, 49: 1622-1628

84 Cunha-Vaz J, Ribeiro L, Lobo C. Phenotypes and biomarkers of diabetic retinopathy. Prog Retinal Eye Res, 2014, 41: 90-111
85 Jackson GR, Scott IU, Quillen DA, Walter LE, Gardner TW. Inner retinal visual dysfunction is a sensitive marker of non-proliferative diabetic retinopathy. British J Ophthalmol, 2012, 96: 699-703

86 Holfort SK, Jackson GR, Larsen M. Dark adaptation during transient hyperglycemia in type 2 diabetes. Exp Eye Res, 2010, 91: 710-714

87 Jackson GR, Barber AJ. Visual dysfunction associated with diabetic retinopathy. Curr Diabetes Rep, 2010, 10: 380-384

88 Somfai GM, Tatrai E, Laurik L, Varga B, Olvedy V, Jiang H, Wang J, Smiddy WE, Somogyi A, DeBuc DC. Automated classifiers for early detection and diagnosis of retinopathy in diabetic eyes. BMC Bioinformatics, 2014, 15: 106

Open Access This article is distributed under the terms of the Creative Commons Attribution License which permits any use, distribution, and reproduction in any medium, provided the original author(s) and source are credited. 